\title{
Obesity: a by-product of trade or attitude?
}

Johnathan Watkins ${ }^{1,2}$, Wahyu Wulaningsih ${ }^{1,3}$

${ }^{1}$ PILAR Research and Education, 20 Station Road, Cambridge, UK, CB1 2JD

${ }^{2}$ Institute for Mathematical and Molecular Biomedicine, King's College London, London, UK, SE1 1UL

${ }^{3} \mathrm{MRC}$ Unit for Lifelong Health and Ageing, University College London, London, UK, WC1B 5JU

Email addresses: jw01@ @ilar.org.uk and wahyu.wulaningsih@ucl.ac.uk

Telephone number: +44 2078486168

$* * *$

Camilleri and colleagues report that intuitive eating, defined as unconstrained food intake in response to physiological rather than emotional cues, is inversely associated with overweight and obesity (1). This study was conducted in a French cohort as part of the NutriNet-Santé study, and suggests that controlling the motives for eating may be a viable public health policy for preventing or reducing obesity. Further work using NutriNet-Santé data found that eating for pleasure is positively associated with overweight (2).

Time-series survey data on the prevalence of obesity in ten countries, including France, show that Anglophone countries and Mexico (whose biggest trading partner is the United States) have higher obesity levels as well as steeper growth trajectories than those of Switzerland, Italy, Spain, South Korea and France [see Figure 2 (3)]. The important NutriNet-Santé studies, therefore, beg the question of whether different motives for eating can also explain the differential levels and growth rates of obesity between countries. A working hypothesis could be framed thus: intuitive eating is less prevalent in high-obesity countries than in low-obesity countries, and may be the driver behind differential obesity levels. However, no empirical evidence exists to support the notion that the populations of countries with high levels and high growth rates of obesity are more likely to eat non-intuitively than those with lower levels and growth rates. 
A recent view proposed that differential attachment to traditional cuisines based on their respective blandness was the possible explanation behind differences in the rise of obesity between countries (4). However, we note that the traditional cuisines of Germany and the Low Countries are very similar to British cuisine; yet these countries have lower levels of obesity (3).

As such, we nominate a possibly more relevant driver of differential obesity levels and growth rates: trade patterns with the United States (US), which, for better or for worse, has been the primary innovator in the production of high-throughput, typically high-calorific, convenience food. The working hypothesis for this proposal is that those countries that were the US' biggest trading partners, especially of processed foods, experienced the steepest rise in obesity. To provide preliminary support for this hypothesis, we extracted the custom-value exports of sugar confectionery (Standard International Trade Classification: 062) (5) from the US to the nine countries shown in Figure 2 of ref. (3). We found that countries with high levels of obesity in the latter half of the 1990s as per ref. (3) generally imported a higher dollar-value amount of sugar confectionery from the US (Figure 1). Australia was the lone high-obesity exception to this phenomenon. However, widening this inquiry to other countries like China and India, as well as adjustment for potential confounders like population size and structure are needed to fully investigate these observations.

In summary, systematic and robust analyses of the spectrum of possible determinants, including intuitive eating and trade patterns, will provide the insights needed to uncover and tackle the origins of rapid rises in obesity.

Word count: 490

\section{References}

1. Camilleri GM, Méjean C, Bellisle F, et al. Intuitive eating is inversely associated with body weight status in the general population-based NutriNetSanté study. Obesity 2016;24:1154-1161.

2. Ducrot P, Fassier P, Méjean C, Allès B, Hercberg S, Péneau S. Association between Motives for Dish Choices during Home Meal Preparation and Weight Status in the NutriNet-Santé Study. Nutrients 2016;8:413. 
3. OECD. Obesity Update. [WWW document]. URL http://www.oecd.org/health/Obesity-Update-2014.pdf

4. Frank J. Origins of the obesity pandemic can be analysed. Nature 2016;532:149-149.

5. US Government Census Bureau. (2016). US International Trade Statistics. [WWW document]. URL http://censtats.census.gov/cgi-bin/sitc/sitcMonth.pl

\section{Figure legend}

Figure 1. Differences between US sugar-confectionery exports to high-obesity and low-obesity countries. Data are shown for four consecutive years, 1996, 1997, 1998 and 1999, when US sugar-confectionery exports and obesity levels were available for the nine (excluding the US) countries in Figure 2 from ref (3). Highobesity level countries are: Australia, Canada, Mexico and UK/England. Low-obesity level countries are Switzerland, Italy, Spain, South Korea and France. Data points indicate the sugar-confectionery custom-value exports from the US to these countries in thousands of US dollars. Middle bars denote the median value and outer bars delimit quartiles. The small sample size means that differences between countries were non-significant by Wilcoxon rank-sum tests. Larger sample sizes and regression analyses to account for possible confounders are needed to fully discern the relationships suggested by these data. 